\title{
PREFACE: COMPUTATIONAL EXPERIMENTS IN AEROACOUSTICS
}

We offer you a special Issue of TSAGI Science Journal. This issue consists mainly of the papers based on the reports from the 4th Russian Conference on Computational Experiments in Aeroacoustics. This conference took place on the coast of the Baltic Sea in Svetlogorsk, Kaliningrad Region, Russia, on September 17-22, 2012. The conference was partially supported by the Central Aerohydrodynamic Institute (TsAGI). The main goal of the Computational Experiments in Aeroacoustics Conference was to discuss modern approaches to numerical simulation of aerodynamic noise and their application in solving urgent problems in aeroacoustics. The papers presented in this special issue of TsAGI Science Journal cover the main topics of the conference.

\section{V. Egorov}

Associate Editor

Central Aerohydrodynamic Institute (TsAGI)

Zhukovsky, Moscow Region, Russia 
